\title{
Frequency analysis of representative flood control water level stations in Puyang River
}

\author{
Yang Wang, Shuhui Zhang*, Ziyi Zhang, Caichao Su, Peng Ding, Guangtian Cao \\ Zhejiang Tongji Vocational College of Science and Technology, Hangzhou 311231, China
}

\begin{abstract}
Puyang river basin is located in the north central part of Zhejiang Province, which is one of the most important river basins in Zhejiang Province. The lower reaches of Puyang River are easily influenced by tide in Hangzhou Bay and flood in Qiantang River. When Puyang river floods, it often meets Fuchun River and floods occur at the same time. The flood discharge of Puyang river is blocked and the water level rises and rises, which makes the Puyang River vulnerable to disaster. Water level frequency analysis is the basis of Puyang river planning and flood control plan. The representative flood control water level stations of Puyang River include Zhuji station and wenjiayan station. The frequency analysis of these representative stations is helpful to determine the water level of these key nodes under different frequencies, and to provide basic data for accurate flood control of Puyang River and ensure the safety of flood control.
\end{abstract}

\section{Introduction}

Puyang river is located in the north central part of Zhejiang Province and the west part of xiaoshaoning area. It is adjacent to Longmen Mountain and its remaining veins in the West and south, Kuaiji mountain in the East, and Hangzhou Bay of Taihu Lake in the north, with a drainage area of $3431 \mathrm{~km} 2$. The Puyang river basin is slightly elliptical, surrounded by mountains in the East, South and West. The hilly area accounts for $70 \%$ of the total area, and the plain accounts for $30 \%$. The highest mountain in the basin is Dongbai mountain, with an altitude of 1193 M. The lower reaches of Puyang River are easily influenced by tide in Hangzhou Bay and flood in Qiantang River. When the Puyang river floods, it often meets the Fuchun River and floods at the same time. At this time, the Puyang River flood (the reach below Zhuji Chengguan) will be blocked, and the water level will rise and rise. Therefore, if the Puyang river floods, if the downstream spring tide or flood butts, the flood discharge is not smooth, which is very easy to cause flood stagnation in the vicinity of Zhuji Chengguan Meichi area, seriously endangering the safety of farmland villages and towns on both sides of the Strait and the Zhejiang trunk railway, and easily lead to serious disasters.

Water level frequency analysis is the basis of Puyang river planning and flood control plan. The representative flood control water level stations of Puyang River include Zhuji station and wenjiayan station. The frequency analysis of these representative stations is helpful to determine the water level of these key nodes under different frequencies, and to provide basic data for accurate flood control of Puyang River and ensure the safety of flood control.

\section{Overview of main flood control projects of Puyang River}

Since the founding of new China, Puyang river has carried out flood control four times. At present, the embankment along the main stream of Puyang River on one side of the railway basically meets the design standard of 50-year return period, other embankments along the main stream basically meet the design standard of 20-year return period, and the construction of Fengqiao river reaches the design standard of 10-year return period.

Since the founding of new China, a large number of reservoir projects have been built in the upper reaches of the basin, including 2 large (II) reservoirs, 9 mediumsized reservoirs, 37 small (I) reservoirs and 199 small (II) reservoirs. Only large and medium-sized reservoirs have a total storage capacity of 536.4 million $\mathrm{m} 3$, of which the flood control storage capacity is 186 million $\mathrm{m} 3$ (including high lake), accounting for $37.3 \%$ of the total storage capacity. In addition, a high Lake flood detention reservoir will be built at Chengguan, Zhuji in the middle reaches. In the past floods, these reservoirs have played a great role in retaining floods, reducing flood peaks and reducing the flood control pressure downstream.

\footnotetext{
${ }^{*}$ Corresponding author: 1411658545@qq.com
} 


\section{Disastrous rain pattern and flood}

Puyang river basin is a subtropical monsoon climate area with mild climate and significant monsoon. Frontal rain often stays over the basin in spring and summer to form strong Meiyu rainstorm. Short duration and high-intensity typhoon rainstorm will be formed in case of tropical storm and typhoon in summer and autumn. Puyang River Basin belongs to the concurrent area of Meiyu and Taiyu. The middle and upper reaches are mainly controlled by Taiyu and the lower reaches are mainly controlled by Meiyu. Puyang river is a typical mountain stream River, with a large mountainous area, the shape of the basin is quite fanshaped, and mountain torrents are easy to gather; The middle and lower reaches have flat and low-lying terrain, slow water flow, narrow river channel and poor drainage; Affected by the tide of Hangzhou Bay and the flood jacking of Qiantang River, the water level in the lower reaches is easy to rise.

Puyang river basin is known as the "Little Yellow River" because of its frequent floods. According to historical records, floods mostly occur in spring and summer. In the 915 years from 1034 to 1949, there were 106 major floods, of which 13 were flooded in Zhuji Chengguan. The flood in 1922 was the most serious flood in the modern history of Puyang river. Since the founding of new China, there have been 13 major floods, with an average of once every four years. Among them, the "6.19" flood in 1956, the "9.6" flood in 1962, the "6.17" flood in 1977, the "6.17" flood in 1994 and the "7.9" flood in 1997 are the most serious.

Table 1. Causes of major floods in Puyang River after the founding of the people's Republic of China

\begin{tabular}{|c|c|c|c|c|}
\hline \multirow{2}{*}{ time } & \multicolumn{2}{|c|}{$\begin{array}{l}\text { Average rainfall } \\
\text { in the basin }\end{array}$} & \multirow{2}{*}{$\begin{array}{c}\text { Water level of } \\
\begin{array}{c}\text { Zhuji Taiping } \\
\text { Bridge }\end{array} \\
\text { (m) }\end{array}$} & \multirow{2}{*}{ origin } \\
\hline & $\begin{array}{l}\text { One } \\
\text { day }\end{array}$ & $\begin{array}{l}\text { Three } \\
\text { days }\end{array}$ & & \\
\hline \multirow{2}{*}{1950.6 .24} & & & 12.55 & \multirow{2}{*}{ mould rains } \\
\hline & & & -14.37 & \\
\hline \multirow{2}{*}{1952.6 .1} & & & 12.7 & \multirow{2}{*}{ mould rains } \\
\hline & & & -14.52 & \\
\hline \multirow{2}{*}{ 1953.7.1 } & \multirow{2}{*}{83.8} & \multirow{2}{*}{108.1} & 12.63 & \multirow{2}{*}{ mould rains } \\
\hline & & & -14.45 & \\
\hline \multirow{2}{*}{ 1954.5.26 } & \multirow{2}{*}{76.6} & \multirow{2}{*}{118.5} & 12.4 & \multirow{2}{*}{ mould rains } \\
\hline & & & -14.22 & \\
\hline \multirow{2}{*}{ 1955.6.19 } & \multirow{2}{*}{96} & \multirow{2}{*}{106.8} & 12.49 & \multirow{2}{*}{ mould rains } \\
\hline & & & -14.31 & \\
\hline \multirow{2}{*}{ 1956.8.2 } & \multirow{2}{*}{181.2} & \multirow{2}{*}{203.7} & 13.05 & \multirow{2}{*}{ typhoon } \\
\hline & & & -14.87 & \\
\hline \multirow{2}{*}{1961.10 .5} & \multirow{2}{*}{90} & \multirow{2}{*}{143.8} & 12.18 & \multirow{2}{*}{ typhoon } \\
\hline & & & -14 & \\
\hline \multirow{2}{*}{1962.9 .6} & \multirow{2}{*}{196.6} & \multirow{2}{*}{257.5} & 13.01 & \multirow{2}{*}{ typhoon } \\
\hline & & & -14.83 & \\
\hline \multirow{2}{*}{1970.6 .26} & 718 & 1228 & 12.71 & \\
\hline & 71.8 & 132.8 & -14.53 & mould rains \\
\hline 1073517 & 678 & 1323 & 12.76 & soft spring \\
\hline 1973.5 .17 & 67.8 & 133.3 & -14.58 & rain \\
\hline 1977617 & 117 & 1520 & 13 & \\
\hline $197 / .6 .17$ & 117 & 152.9 & -14.82 & mould rains \\
\hline 1994617 & 115 & & 12.4 & \\
\hline 1994.6.17 & 115 & 206 & -14.22 & mould rains \\
\hline 1997.7 .9 & 137.8 & 244 & 12.7 & mould rains \\
\hline & $13 / .8$ & 244 & -14.52 & \\
\hline
\end{tabular}

\section{Pearson type III curve analysis method}

Pearson type III frequency curve is recommended to be used in hydrological statistics [1-3]. Pearson type III curve [4-5] is an unsymmetrical unimodal and positive skew curve with a finite end and an infinite end,The probability density function is as follows:

$$
f(x)=\frac{\beta^{\alpha}}{\Gamma(\alpha)}\left(x-\alpha_{0}\right)^{\alpha-1} e^{-\beta\left(x-a_{0}\right)}
$$

Where: $\Gamma(\alpha)$ - gamma function of $\alpha$;

$\alpha \beta$ and $\alpha_{0}$ are the shape scale and position unknown parameters of Pearson type III distribution, $\alpha>0, \beta>0$, respectively. Obviously, the density function can be determined after the three parameters are determined. It can be inferred that these three parameters have the following relationship with the overall three parameters $\bar{x}, c_{v}$ and $c_{s}$ :

$$
\begin{gathered}
\alpha=\frac{4}{C_{s}^{2}} \\
\beta=\frac{2}{\bar{x} c_{v} c_{s}} \\
\alpha_{0}=\bar{x}\left(1-\frac{2 c_{v}}{c_{s}}\right)
\end{gathered}
$$

In hydrological calculation, it is generally necessary to calculate the value of random variable xp corresponding to the specified frequency $\mathrm{P}$, that is, by integrating the density curve, that is:

$$
P=P\left(x \geq x_{p}\right)=\frac{\beta^{\alpha}}{\Gamma(\alpha)} \int_{x_{p}}^{\infty}\left(x-\alpha_{0}\right)^{\alpha-1} e^{-\beta\left(x-a_{0}\right)} d x
$$

Find the cumulative frequency $\mathrm{p}$ value equal to or greater than xp. It is very troublesome to calculate the value of $\mathrm{P}$ directly from the above formula. In practice, it is transformed into the following integral form through variable transformation: 


$$
P\left(\Phi \geq \Phi_{p}\right)=\int_{\Phi_{p}}^{\infty} f\left(\Phi \cdot C_{s}\right) d \Phi
$$

In the formula, the integrand contains only one undetermined parameter $c_{s}$, the other two parameters $\bar{x}$ and $c_{v}$ are included in $\Phi . \mathrm{x}$ is a standardized variable called the mean deviation coefficient. $\Phi=\frac{x-\bar{x}}{\bar{x} C_{V}}$ The mean value of $\Phi$ is 0 and the standard deviation is 1 . Therefore, we only need to assume a $c_{v}$ value, then we can get the relationship between and by integration. For some given $c_{s}$ values, The relationship between and $\Phi$ can be obtained by integrating.For several given $c_{s}$ values, Table of corresponding values for $\Phi_{p}$ and $p$ have been made by foster of the United States and leibkin of the former Soviet Union successively. Then the $\mathrm{x}$ value of the corresponding frequency can be obtained:

$$
x=\bar{x}\left(1+C_{V} \Phi\right)
$$

\section{Frequency analysis of representative flood control water level stations in Puyang River}

Zhuji station and wenjiayan station are representative flood control stations of Puyang river. Pearson type III curve is used to analyze their frequency. The analysis results are shown in Figure 1.

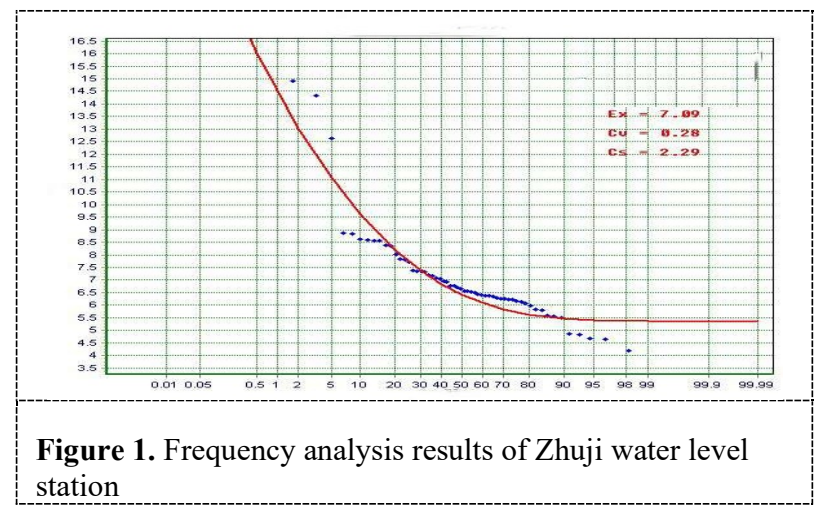

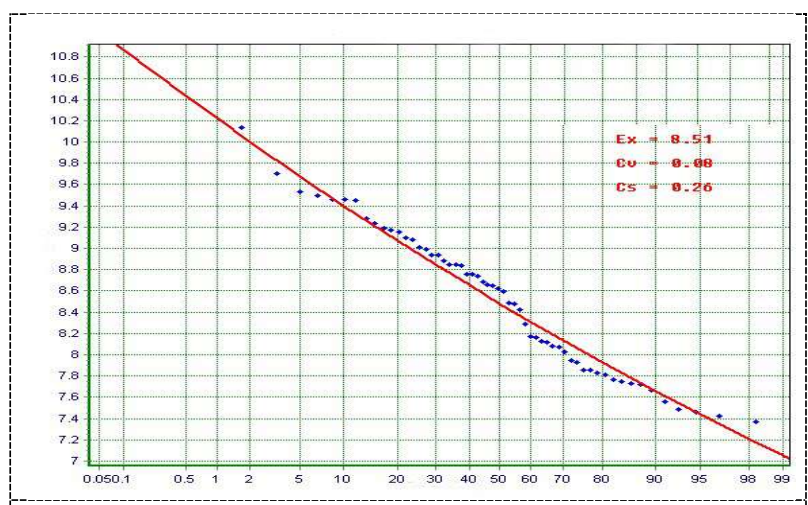

Figure 2. Frequency analysis results of Wenjiayan water level station

Table 2. Water level values of each frequency at Zhuji station

\begin{tabular}{c|c|c|c|c|c}
\hline $\begin{array}{c}\text { Frequency } \\
(\%)\end{array}$ & 0.1 & 0.2 & 0.3333 & 0.5 & 1 \\
\hline Design value & 19.56 & 18.04 & 16.92 & 16.04 & 14.53 \\
\hline $\begin{array}{c}\text { Frequency } \\
(\%)\end{array}$ & 2 & 3.3333 & 5 & 10 & 20 \\
\hline Design value & 13.04 & 11.94 & 11.08 & 9.62 & 8.2 \\
\hline
\end{tabular}

Table 3. Water level values of each frequency at wenjiayan station

\begin{tabular}{c|c|c|c|c|c}
\hline $\begin{array}{c}\text { frequency( } \\
\%)\end{array}$ & 0.1 & 0.2 & $\begin{array}{c}0.333 \\
3\end{array}$ & 0.5 & 1 \\
\hline $\begin{array}{c}\text { Design } \\
\text { value }\end{array}$ & $\begin{array}{c}10.8 \\
7\end{array}$ & 10.69 & 10.54 & $\begin{array}{c}10.4 \\
3\end{array}$ & $\begin{array}{c}10.2 \\
2\end{array}$ \\
\hline $\begin{array}{c}\text { frequency( } \\
\%)\end{array}$ & 2 & $\begin{array}{c}3.333 \\
3\end{array}$ & 5 & 10 & 20 \\
\hline $\begin{array}{c}\text { Design } \\
\text { value }\end{array}$ & 10 & 9.83 & 9.68 & 9.4 & 9.07 \\
\hline
\end{tabular}

\section{Conclusion}

This paper analyzes the frequency of Puyang River flood control representative station by Pearson type III curve analysis method. Through the analysis, the water level values of Zhuji station and wenjiayan station under different frequencies are obtained. These water level values are the basis of flood control planning and flood control plan of Puyang river. The data can provide basic support for flood control decision-making and flood control advance deployment of Puyang river.

\section{Acknowledgments}

This work was financially supported by Water conservancy science and technology plan project of Zhejiang Province (Project No.RC2008) fund. 


\section{References}

1. Xie chongbao, Yuan Hongyuan, Guo Yuanyu. Parameter estimation of P - III theoretical frequency curve -- fuzzy extreme value method [J]. Hydrology, 1997 (03): 2-9

2. Li Shicai, Peng Yueying, Wei Wenzhan. A new numerical algorithm for Pearson type III curve and its application $[\mathrm{J}]$. Guangxi water resources and hydropower, 2001 (01): 18-23

3. Che Guowen. Excel drawing method of Pearson type III curve [J]. journal of liaoning teachers college (natural science edtitton), 2018,20 (04): 9-11 + 108 .

4. John L. Carlson. A Study of the Distribution of Means Estimated From Small Samples by the Method of Maximum Likelihood for Pearson's Type II Curve. 1932, 3(2):86-107.

5. Small-Sample Asymptotic Distributions of MEstimators of Location. 1982, 69(1):29-46. 